\title{
1. Practising Political Life Writing in the Pacific
}

\author{
Jack Corbett
}

... biography is not solely a quest to imagine and transform the other. No. It is also a quest to understand and transform the self through a journey mediated by feeling and self-discovery. ${ }^{1}$

The state of life writing in the Pacific presents us with something of a paradox. On the one hand, on a country-by-country basis, there seem to be numerous gaps, with academics the primary authors of the few lives that have been written. On the other hand, as Doug Munro has remarked, when taken as a group, the corpus of life writing in the Pacific is one of the most substantial bodies of work about the politics and history of the region. ${ }^{2}$ Certainly, when it comes to the study of leadership and political leadership in particular, nothing from the mainstream academic disciplines rivals its breadth and depth, which is especially remarkable given that much of this writing is of recent - that is, post-colonial origin. This point is argued most persuasively by Jonathan Ritchie's contribution to this volume, which focuses specifically on the state of the life writing art in Papua New Guinea, but it is of more general relevance. Academic and popular commentators in the Pacific regularly observe that politics tends to be heavily personalised, highlighting the ways that governments and coalitions rise and fall on the strength of their leaders. In this context, the individual life takes on added significance than it might elsewhere. Despite this, life writing generally, and life writing about political figures in particular, is a recent development and as such tends not to be based on a wide reading of the available literature. There is comparatively little reflexive analysis about how these texts have been created and what they contribute to mainstream disciplinary approaches.

Reflecting this discrepancy, a number of edited collections dedicated to the art of life writing have recently attempted to fill the void. The Stewart and Strathern volume Identity Work: Constructing Pacific Lives addresses several life writing themes of immediate concern to anthropologists and debates about Melanesian ethnography, including the nature of personhood, self, and sense of place and gender. ${ }^{3}$ A year later, Lal and Hempenstall edited the Pacific Lives,

1 R. Morley, ‘Fighting Feeling: Re-thinking Biographical Praxis', Life Writing, 9: 1 (2012), 79.

2 D. Munro, 'Would the Biographers Please Stand up', in B. Lal and P. Hempenstall (eds), Pacific Lives, Pacific Places: Bursting Boundaries in Pacific History (Canberra 2001).

3 P.J. Stewart and A. Strathern, Identity Work: Constructing Pacific Lives (Pittsburgh 2000). 
Pacific Places: Bursting Boundaries in Pacific History collection which, in many respects, provided an historian's perspective on these same themes - although the answers each discipline delivered were very different. ${ }^{4}$ Where anthropologists have tended to see autobiography and biography as presuming a 'western' understanding of the individual subject that is alien to Pacific cultures, the Lal and Hempenstall volume sees life writing as a counterpoint to this characterisation of Islanders as acting solely through a cultural template. ${ }^{5}$ Instead, they recognise the capacity of life history to provide a sense of human agency often missing from structuralist accounts. These tensions are deeply embedded in the scholarly literature more generally, but life writing has been one avenue where these debates have surfaced in the Pacific context.

The most recent addition is the Lal and Luker volume Telling Pacific Lives: Prisms of Process. ${ }^{6}$ An explicitly multidisciplinary and wide-ranging endeavour, this book takes on the existing debate between historians and anthropologists about the place of culture and world view in Pacific life writing - although it does not resolve it. Where it differs from previous attempts, aside from being significantly longer with more contributors, is in its focus on life writing practice. We learn more about the process of conducting research - about how relationships are negotiated and information is accessed, verified and interpreted. That is not to say the two previous volumes ignored this topic - ethnographic reflexivity is a core theme in Stewart and Strathern's book, for example - but the Lal and Luker volume puts the issue front of stage. ${ }^{7}$ They conclude that "Telling [1]ives" is an intricate and contested exercise' that is complicated 'in cross-cultural and non-literate contexts where notions of time, space, history, myth, the role and obligations of individuals in society differ greatly and where, moreover, historical memory is not archived. ${ }^{8}$ They ask: 'How, in these situations, do we construct lives?' The answer, they contend, 'varies enormously depending on the teller's discipline as well as the subject's circumstance and context. If "making bare the poor dead secrets of the heart" is the task, it is not easy, never was. ${ }^{\prime 9}$

As something of a successor to the Telling Pacific Lives project, this volume takes its cue from their description of the complexity and negotiation embedded in the practice of life writing. The contributions assembled here vary significantly in terms of circumstance and discipline, aim and method. This is a collection of authorial reflections about how they have gone about writing a life, what the experience was like, and what they have learnt through the process. Axiomatically, by looking across these accounts we appreciate that

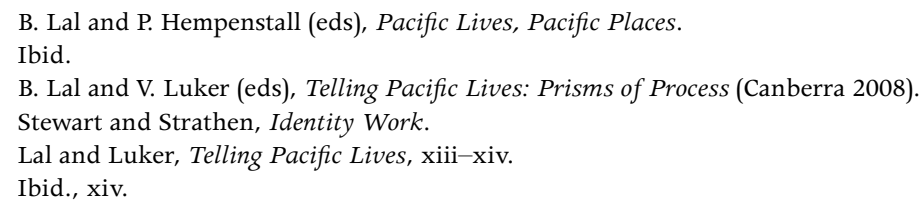


there is no set formula for writing a life, political or otherwise. Rather, we see how each author has, in their own way, negotiated the myriad of overlapping issues and tensions that Lal and Luker describe. However, while each instance is unique, there are patterns, themes and lessons that offer guidance to future practitioners. Accordingly, while this book does not provide a theoretical or practical road map on how to write a political life, it contains numerous insights about the types of obstacles that authors encounter along the way, and offers some reflections on how they went about overcoming them.

The obvious point of departure from the Lal and Luker volume is the emphasis on writing 'political' lives. So, let me begin by getting the definitional questions out of the way. Defining what constitutes a 'political' life is fraught and all such attempts are necessarily porous in practice. More than any of the conventional disciplines, life writing muddies attempts to distinguish between personal and political. Consequently, in conceptualising our initial workshop, Brij and I left the 'what is and is not political' question open, allowing authors to selfidentify their work. However, like all categorisations, we had in mind a group of texts that we felt formed the core of a genre. This group comprised more than 40 autobiographies, biographies, and collections of writings and speeches written by or about politicians in the Pacific Islands. ${ }^{10}$ This is in many respects an unwieldy group that, as evidenced by the chapters in this book on new projects, is growing yearly. The earliest example is an autobiographical book written by Sir Tom Davis - who later became Prime Minister of the Cook Islands - and his first wife Lydia, ${ }^{11}$ while the latest is David Hanlon's life of Tosiwo Nakayama. ${ }^{12}$ In a broader sense, if we begin to include other political figures - colonial governors, chiefs and prominent clergy for example - the list gets longer and the dates older.

A similar point can be made about the organisation of this book around a geographic location. The life stories of politicians mentioned above all come from the 14 independent and self-governing political entities in the Pacific region. However, they are not spread evenly as there is a greater concentration of works from Fiji, Papua New Guinea and Solomon Islands relative to other parts of the Pacific. That is, the bulk of the writing, political and otherwise, has focused on the Melanesian region. This book includes chapters from outside the Melanesian region which, while adding a contrasting perspective, also highlight some of the distinctive aspects of life writing in Melanesia. For example, Munro's chapter on life writing about New Zealand's prime ministers brings the relative newness of the Pacific literature into sharp focus. The genre in New Zealand is

10 For review, see J. Corbett, “"Two Worlds?” Interpreting Leadership Narratives in the 20th Century Pacific', Journal of Pacific History, 47: 1 (2012), 69-91.

11 T. Davis and L. Davis, Doctor to the Islands (London 1955).

12 D. Hanlon, Making Micronesia: A Political Biography of Tosiwo Nakayama (Honolulu 2014). 
well established and forms part of a larger intellectual discourse. By contrast, life writing in the Pacific Islands has tended to be an occasional art practised by academics - for nearly all of the contributors to this volume, life writing makes up only a small portion of their principal work - and other enthusiasts, all of whom have tended to be outsiders.

Without labouring the point, the term 'life history' raises the same issues. As above, it is predominantly employed in this book to capture a variety of materials, the bulk of which fall into the conventional categories of autobiography and biography, along with edited collections of speeches and diaries. However, there are many other ways to record a life, including via film, which is the subject of Ceridwen Spark's chapter. Indeed, some of the most famous life histories written about political figures in the Pacific region - for example, the Ulli Beier assisted life of former Deputy Prime Minister of Papua New Guinea, Albert Maori Kiki; ${ }^{13}$ the Roger Keesing edited book on former Solomon Islands Minister Jonathan Fifi'i; ${ }^{14}$ or the Judith Bennett and Khyla Russell edited life of the former Speaker of the Solomon Islands parliament, Lloyd Maepeza Gina $^{15}$ - were initially recorded as interviews before they became substantive texts. There have also been several attempts at writing a collection of lives. The Davidson and Scarr edited Pacific Islands Portraits ${ }^{16}$ and Deryck Scarr's More Pacific Islands Portraits, ${ }^{17}$ contain short biographical works in the mould of Plutarch's famous Lives, as does the Firth and Tarte edited 20th Century Fiji: People Who Shaped This Nation ${ }^{18}$ and the Pollard and Waring collection Being the First: Storis Blong Oloketa Mere lo Solomon Aelan. ${ }^{19}$

Having outlined the limits of the terms that define the essential parameters of this collection, it is important to say that all three nevertheless serve as a useful shorthand which, while contentious, captures a sense of the people we are talking about, the places they come from, and the ways in which their stories have been recorded and made accessible to a range of audiences. In other words, while all categorisations are somewhat arbitrary, this does not mean they serve no function - quite the opposite. In the context of this book, their usefulness stems from the sense of an ideological Pacific community that, in many respects, has been created by the people we call political leaders and sustained through their writings.

13 A.M. Kiki, Kiki: Ten Thousand Years in a Lifetime, a New Guinea Autobiography (Melbourne 1968).

14 J. Fifi'i, From Pig-Theft to Parliament: My Life Between Two Worlds (Suva 1989).

15 L.M. Gina, Journeys in a Small Canoe: The Life and Times of a Solomon Islander (Canberra 2003).

16 J.W. Davidson and D. Scarr (eds), Pacific Islands Portraits (Canberra 1970).

17 D. Scarr (ed.), More Pacific Islands Portraits (Canberra 1979).

18 S. Firth and S. Tarte, 20th Century Fiji: People Who Shaped This Nation (Suva 2001).

19 A.A. Pollard and M. Waring, Being the First: Storis Blong Oloketa Mere lo Solomon Aelan (Auckland 2009). 
Largely, political life writing in the Pacific has taken on literary and empirical rather than theoretical forms. This partly reflects the nature of the genre which is why it occupies such a contentious place within political studies, both historical and contemporary. Critics of life writing argue that the genre is overly subjective, is not explanatory in orientation, and does not articulate a rigorous methodology. ${ }^{20}$ In particular, the strong relationship between the author and their subject is the source of some ambivalence for scholars concerned with objectivity and scientific rigour. Certainly, the 'great person in history' tendency of the single person narrative sits in stark contrast to conventional disciplinary approaches that portray leaders as products of social, economic and political forces or as responding rationally to institutionally structured incentives. ${ }^{21}$ However, this type of approach has limits, not the least of which is the inability to consider the human dimension of political life. This takes on particular significance in the Pacific where writers grapple with topics that tend to fall outside the purview of biographical scholarship. Both Nicole Haley and Clive Moore's subjects, for example, emphasise the importance of spirituality, including dreams and premonitions, in the lives they consider.

In addition to the overarching rationale for this book - to reflect on how writers have gone about constructing political life histories - it also serves as a response to the ambiguity with which the genre is treated by mainstream disciplines. Political life writing, as David Hanlon outlines, provides a 'critical focal lens' through which we can examine a host of key themes and debates pertinent to the contemporary Pacific in particular, and the study of politics in general. ${ }^{22}$ However, to support the veracity of these claims we need to understand how political lives are written and consider how each author leaves their own imprint on the text. This is true of all life writing but takes on added significance in the context of political figures.

Political life histories are more than mere stories about politicians or influential men and women - they focalise wider ideals, values and aspirations and, in the case of independence leaders, embody the story of a nation. ${ }^{23}$ The importance of retelling the story of Vanuatu's independence struggle is central to former Deputy Prime Minister, Reverend Sethy Regenvanu's chapter in this collection. Regenvanu describes his motivation for writing autobiography as stemming

\footnotetext{
20 T. Arklay, J. Nethercote and J. Wanna, 'Preface', in T. Arklay, J. Nethercote and J. Wanna (eds), Australian Political Lives (Canberra 2006), xi.

21 T. Arklay et al., Australian Political Lives; R.A.W. Rhodes, 'Theory, Method and British Political History', Political Science Review, 10: 2 (2012), 161-76.

22 D. Hanlon, “'You Did What, Mr President!?!?" Trying to Write a Biography of Tosiwo Nakayama', in B. Lal and V. Luker (eds), Telling Pacific Lives (Canberra 2008), 167.

23 P. Holden, 'A Man and an Island: Gender and Nation in Lee Kuan Yew's the Singapore Story', Biography, 24: 2 (2001), 401-24; D. Morais, 'Malaysia: The Writing of Lives and the Constructing of Nation', Biography, 33: 1 (2010), 84-109.
} 
in part from anger at how his political career ended but also, as one of the founding fathers of the nation, out of a sense of duty to record the past for future generations. ${ }^{24}$ His chapter, like his book, presents a passionate case for why autobiography, which often attracts even greater suspicion than biography in the eyes of many mainstream scholars, is an important medium for recording memories. Specifically, he argues that it provides an account of events as seen through the eyes of somebody who lived it, experienced it, and who knows what the burdens and pressures of holding public office are like.

In a distinct but similar vein, Brij Lal's chapter addresses the same question. Daunted by the prospect of turning all of his carefully collected data into a substantive text, Lal describes receiving the impetus to finish his biographical manuscript from a group of high school students who, despite his considerable significance to Fiji's contemporary history, did not know who former Leader of the Opposition Jai Ram Reddy was. Like Regenvanu, Lal describes how he approached writing with a sense of fury that stemmed from a desire to not only capture the essence of his subject's public persona, but to set the record straight and ensure that Reddy and the party he represented was not expunged from the historical record: 'I write because I have to, to bear witness to the time in which I have lived. I see writing as an act of revenge against a culture of indifference and forgetfulness, an act of revenge against historical amnesia' (Chapter 5). In contrast, Christopher Chevalier outlines in his contribution how he writes about former Prime Minister of Solomon Islands, Solomon Mamaloni, 'to repay a debt to Solomon Islands for having given me an adopted daughter and more than 20 years of fascinating work, travel and study' (Chapter 3).

The strong relationship between author and subject is particularly apparent in Nicole Haley's chapter about Sane Noma, a ritual leader, land mediator and visionary from Lake Kopiago District, Papua New Guinea. She writes 'to honour the life and memory of Sane Noma' (Chapter 8). Haley describes how Noma has informed or inspired almost every piece of academic writing she has ever written. More significantly, his prophecies are of great importance to her life and that of her daughter Aliria. However, despite the significance of Noma's life, and the window it offers into a century of dramatic change in Papua New Guinea, Haley relates struggling with one question in particular: how to tell his story. She wonders how her relationship with Noma will be received and describes a sense of trepidation at the potential ridicule the type of personal account, which would do justice to her subject, might attract in the academy. Nonetheless, she is prepared to brave the odds and defy scholarly conventions to give us her account of a sensitive engagement with a world beyond the realm of traditional scholarship. 
As Doug Munro's chapter poignantly illustrates, the connection between an author and their subject is central to any theoretical or practical conceptualisation of biographical writing. It is normally assumed that for one person to dedicate so much of their time to the study of somebody else's life there must be an important bond that links these two people. Sometimes there is, as in the case of Lal and Reddy or Haley and Noma. In other instances, as Deryck Scarr's chapter illustrates, chance and fortune play a significant role in pairing an author and their subject. Like many life writers, serendipity, Scarr recalls, brought him to the Pacific and had a hand in his decision to write a two-volume biography of Sir John Bates Thurston, Governor of Fiji, which imposed itself on him during his work in the Western Pacific High Commission archives. Similarly, Scarr describes being approached unawares by the selection committee tasked with finding a biographer to write the life of Fijian statesman Ratu Sir Lala Sukuna. Based on the success of the Sukuna book, he further explains how he felt that a life of Sukuna's onetime protégé, inaugural Prime Minister and former President of Fiji, Ratu Sir Kamisese Mara, 'was rather expected of me' (Chapter 6). That is not to say Scarr wrote on a whim - the interest of the subject, the availability of materials and the political significance of the latter two subjects, we can infer, were key considerations - but that writing biography is often something people stumble upon rather than set out to do.

Somewhat scarcer than reflection on the relationship between author and subject, but of great significance in the Pacific where nearly all political autobiographies have been compiled with some assistance, is consideration of the role of editing a life or a collection of lives. This is the subject that Clive Moore tackles and his thoughts reveal several interrelated themes. The first concerns recognition. Editing a life or a collection of lives requires the investment of an enormous amount of time and yet this commitment remains largely undervalued by those who judge academic outputs. This quandary, Moore relates, is often under-appreciated by his subjects. One solution he explores is the possibility of becoming a co-author of his latest project, the life of former Minister and Governor-General of Solomon Islands, Sir Nathaniel Waena, thus side-stepping the bureaucratic requirements of the academy. But, as he concedes, it also entails greater ownership of the content - creating new problems and questions about historical veracity and authorial integrity.

The Moore chapter raises several themes that are taken up by other contributors to this book, including the nature of source materials used to compile political lives. Each author, as Munro highlights, solves this problem differently depending on their subject and the type of life they want to write. In the case of his current subject, Moore grapples with how to interpret and incorporate the significance of premonitions and dreams in early drafts. As he relates, there is something refreshing about the way these private experiences are related but he 
wonders how a book is to be made from such material. He, and several others, make a similar point about Christianity. A Christian faith is central to how most Pacific Islanders understand and give meaning to their lives and yet this spiritual commitment is often foreign to the academics that assist with editing or writing their life stories. None of the chapters resolves this dilemma but all concede that, in some way, this disjuncture has had some impact on the final product.

Locating and accessing the information required to write a life is a common challenge for all practitioners. However, there is something about securing interviews that is both distinctively demanding and uniquely rewarding. This point is made with particular force in Areti Metuamate's chapter on writing the life of the late Tupou V, King of Tonga. Where all interviewers have to confront questions of permission and access, Metuamate also describes learning and observing the protocols that surround a subject like the King of Tonga. What's more, many of the King's friends - Sir Michael Hill the jeweller, Lord Glenarthur of Britain and the King of Bhutan - who could talk with some authority on the nature of the man, are not easily accessible. Despite acknowledging inevitable mistakes and the providential hand of Facebook, Metuamate expresses gratitude for the generosity of his interviewees.

The willingness of informants is also a theme that Christopher Chevalier addresses when reflecting on writing a life of Mamaloni. Interviews, says Chevalier (Chapter 3), 'provided original and fascinating insights not available from the public record'. Where Chevalier and Metuamate disagree is with respect to how far a biographer should probe the life of their subject. Chevalier, perhaps conscious of the complexity of Mamaloni's private life - he had four wives in a highly Christianised country - stands true to the adage that a biographer 'should go up to the bedroom door but do[es] not go beyond'. But Metuamate, whose subject had a much-commented-upon private life, disagrees and argues instead that public figures forgo a certain amount of privacy by virtue of the office they hold. This discussion is particularly pertinent to political life writing in the Pacific as it forces us to consider what public office means in this context, and what types of norms and standards govern how public roles are understood and reinterpreted, both by biographers and constituents.

While every situation is unique, retrieving and interpreting written or oral data is nevertheless a well-trodden path in scholarly work. Certainly, even if insights come in the form of dreams and premonitions, the mode of delivery, be it oral or written, is not alien to most researchers, even if certain disciplines privilege different sources. Film, on the other hand, is relatively unique and certainly, as a medium for political biography, its use is less common in the Pacific. However, as Ceridwen Spark argues in her chapter about the 'Pawa Meri' project in Papua New Guinea, film can be an incredibly powerful way of telling a life story. Significantly, Spark argues, unmediated by the academy, many Pacific 
filmmakers are documenting their own stories and those of their relatives and fellow villagers, and communicating them to audiences all over the world via the internet. Like Moore, Spark has sought to be a facilitator rather than the primary author of these works with the six documentaries all directed by Papua New Guinean women. Cooperation and compromise are the corner stone of her approach. Spark aims to preserve a narrative that the people themselves will recognise. Metuamate also makes this point: any assessment of individuals must be seen in the context of wider roles and relationship in society, necessitating modification of the genre's conventions.

This type of life history raises many interesting and exciting possibilities. In the context of this book, one of the most important questions Spark raises is: who is the audience? Audience is a theme that runs through former Minister and Leader of the Opposition in Papua New Guinea, Dame Carol Kidu's chapter. Kidu describes how personally rewarding she found the positive reaction to her autobiography A Remarkable Journey, ${ }^{25}$ and relates that a number of people have asked her to write a sequel that covers her three terms in parliament. But how would readers want to access this chapter in her life, she wonders aloud? Humorous anecdotes and personal insights would satisfy a larger audience but, she worries, they might seem superficial or frivolous to serious scholars. Certainly, she concedes, a detailed life and times approach would require time and resources that she does not have. Accordingly, the Kidu chapter illustrates some of the barriers that political leaders in the Pacific Islands face in writing their own life stories, not the least of which is that life writing does not pay the bills.

In addressing the audience question with regards to film, Spark argues that Papua New Guineans want to represent and watch themselves. In theory, books also provide an avenue for Pacific Islanders to write and read about themselves. Indeed, as Jonathan Ritchie outlines in his chapter, the need to provide future generations of Pacific Islanders with role models from the past was a central reason for his biography of Ebia Olewale. The assumption, however, as the Lal chapter argues, is that the younger generation are reading. There is a proverbial chicken and egg problem here because, as Regenvanu highlights explicitly but nearly all the authors touch on implicitly, since the closure of the Institute of Pacific Studies at the University of the South Pacific, there are few local avenues through which Pacific scholars can publish their writing. Film and the internet provide new possibilities that may circumvent this problem. However, as the continued reliance of the genre on the input of scholars from Australia, New Zealand and Hawaii in particular highlights, there are considerable inequalities that underpin who writes Pacific lives and who the audience is for these works. 
Both editors know from personal experience of the desire for Pacific Islanders to write their stories - of parents, pastors and places - but they often lack the skills and resources to do so. The relative absence of non-academic publishers, and the size of the market, presents significant barriers. Outsiders step in to fill this void but, as Moore asks, how much influence should they have?

Beyond writing about political figures, the Spark chapter also asks us to consider the politics of writing political lives. She raises two questions: who are considered leaders or role models worth writing about and who can represent them? As outlined, questions about representation are longstanding in disciplinary scholarship on the Pacific but, as Peter Hempenstall argues, they bite hardest in life writing as it seeks to 'reach across cultures and deal with multi-ethnic senses of the self and the person in the Pacific' ${ }^{26}$ However, Spark illustrates that they take on additional significance as donors in particular have become interested in Pacific leadership. The six Pawa Meri films, while directed by Papua New Guinean women, were funded by the Australian aid program and so reflected a particular leadership image they wanted to extol. In some respects, the tendency to celebrate remarkable achievements is an indelible feature of all political life writing. Certainly most of the existing works have been written by or about leaders of some stature who were usually highly educated - often overseas - and who held numerous senior positions in both government and business. However, beyond the general point that life writing tends to attract a certain type of subject, and the warning that donor influence presents a twoedged sword for life writers, Spark's chapter also highlights one of the most obvious features of the genre in the Pacific: it is almost entirely dominated by men.

Given the considerable push to increase women's representation in parliament, Spark asks how we should treat these women as biographical subjects. Should their lives be subjected to less scrutiny in the service of the broader feminist agenda? As the Kidu chapter highlights, there is considerable scope for life writing about women political leaders to reveal the gendered practice of politics in the Pacific and provide inspirational examples of how female politicians make a substantial impact in this predominantly male domain. But, when does biography become hagiography? The answer, Spark concedes, is complicated. By recording the lives of young educated women who are atypical in Papua New Guinea we risk, she argues, misrepresenting who these leaders are while setting up a standard to which most young women in Papua New Guinea cannot aspire. On the other hand 'the exploration of exceptional lives can reveal a privileged person's very ordinariness and humanity' (Chapter 4).

26 P. Hempenstall, 'Introduction, in B.V. Lal and P. Hempenstall (eds), Pacific Lives, Pacific Places (Canberra 2001), 4. 
At the beginning of this chapter I argued that political life writing in the Pacific has predominantly taken a literary and empirical rather than theoretical focus. While largely true - the genre rarely deals with the theoretical questions that occupy biography journals for example - it is also somewhat misleading as it overlooks the dominant metaphor or theme used to describe the way Pacific leaders navigate and define their lives: that they live 'between worlds'. Steeped in modernist precepts, as Ritchie (Chapter 2) illustrates, the use of the metaphor is both pervasive and revealing: 'ten thousand years in a lifetime', 'the stone age to the space age', 'man of two worlds', 'one woman, two cultures'. Despite its appeal, Ritchie points to the limits of this 'obvious and easily adopted' trope, and asks whether it remains useful for understanding leaders into the future, if it ever did in the past.

The use of the 'two worlds' metaphor is, as I have argued elsewhere, an overly simplistic and even unhelpful analytic device for understanding political leadership in the Pacific. ${ }^{27}$ The task then for aspiring political life writers is to find new ways of conceptualising the social setting in which their subjects act. The subtitle of Ritchie's life of Ebia Olewale, A Life of Service, offers one solution here. Indeed, 'service' is not an unpopular metaphor used in Pacific political life writing. He Served is the title of Robert Kiste's (1998) biography of former Fijian Senator Macu Salato, ${ }^{28}$ while former Governor-General of Papua New Guinea, Sir Paulias Matane's autobiography goes by the name To Serve With Love. ${ }^{29}$ In contrast to the stale tradition versus modern dichotomy, what it means to serve a community and a nation via public office, the demands and rewards of acting out political roles, and how the endeavours of leaders are received by the people they represent offers, to borrow Ritchie's words, 'a more nuanced and sophisticated' way into the human dimension of political life. Rather than mimicking the interpretations that dominate mainstream disciplines, life writing has the unique capacity to capture this humanity, but to do so it requires concepts and questions that coherently align with its aims. Exploring the nature of public service in the Pacific Islands offers one such avenue by which life writers can set a new theoretical and empirical research agenda.

This volume then is about political life writing practice in the Pacific Islands. It is not a theoretical treatise but rather a collection of authorial reflections from a variety of disciplinary and personal perspectives, which does not conform to a dictated template, but rather explores how they have gone about writing a life, what the experience was like, and what they have learnt through the process. This is the first step in a long journey, not the last word. There are questions hinted at in this volume that remain unresolved (and are perhaps

27 Corbett, "“Two Worlds?"”.

28 R. Kiste, He Served: A Biography of Macu Salato (Suva 1998).

29 P. Matane, To Serve with Love (Victoria 1992). 
beyond resolution). These include more general reflections about power and culture, and the interpretation of Pacific Island values. But, for now, we leave detailed investigation of these themes for another day. We seek instead to record the experiential side of life writing and to consider what this means for the texts we produce. What emerges is a series of patterns, themes and lessons that will be of benefit to those contemplating writing a life, or merely to those interested in understanding more about the lives that have been written. 
This text is taken from Political Life Writing in the Pacific:

Reflections on Practice, edited by Jack Corbett and Brij V. Lal, published 2015 by ANU Press, The Australian National University, Canberra, Australia. 